\title{
Effect of Mechanical Stresses on Characteristics of Chip Tantalum Capacitors
}

\author{
Alexander Teverovsky \\ Perot Systems \\ Code 562, NASA GSFC, Greenbelt, MD 20771 \\ Alexander.A.Teverovsky.1@gsfc.nasa.gov
}

\section{Abstract}

The effect of compressive mechanical stresses on chip solid tantalum capacitors is investigated by monitoring characteristics of different part types under axial and hydrostatic stresses. Depending on part types, an exponential increase of leakage currents was observed when stresses exceeded 10 $\mathrm{MPa}$ to $40 \mathrm{MPa}$. For the first time, reversible variations of leakage currents (up to two orders of magnitude) with stress have been demonstrated. Mechanical stresses did not cause significant changes of $\mathrm{AC}$ characteristics of the capacitors, whereas breakdown voltages measured during the surge current testing decreased substantially indicating an increased probability of failures of stressed capacitors in low impedance applications. Variations of leakage currents are explained by a combination of two mechanisms: stress-induced scintillations and stress-induced generation of electron traps in the tantalum pentoxide dielectric.

Index terms: Chip tantalum capacitor, mechanical stress, degradation.

\section{Introduction}

Mechanical stresses in microelectronic components might significantly affect their performance and reliability. The ultimate manifestation of these stresses is cracking and fracturing of the component, which results in catastrophic failures. At lower stresses, degradation of characteristics and parametric failures might be due to micro-cracking in active and passive elements or to piezoresistance effects. The latter is known to cause shifts of characteristics in linear devices, such as operational amplifiers and voltage reference microcircuits $[1,2]$ and excessive noise in ceramic capacitors [3].

Surface mount technology (SMT) passive components might experience especially high stresses due to a lack of stress relief. For ceramic capacitors, these stresses result in so-called flex cracking, which was a subject of multiple studies [3-7]. However, no data on the effect of mechanical stresses on chip tantalum capacitors have been found in technical literature.

Some publications indicate that mechanical stresses related to soldering of chip tantalum capacitors might affect their performance and reliability and might be responsible for turn-on breakdowns in the parts [8]. Surge current testing performed by manufacturers to reduce these types of failures may not be sufficient because thermo-mechanical stresses during reflow mounting process can generate new fault sites in the parts [9]. To avoid these failures proofing, or controlled power-up of the system, was suggested [10]. Soldering-induced defects are believed to be caused by excessive CTE of the molding compound when temperature exceeds Tg during the solder reflow process. The effect of soldering was found to be more pronounced for larger sized products, and capacitors manufactured by different vendors showed different sensitivity to soldering [11]. 
In this work, for the first time the effect of mechanical stresses on characteristics of chip tantalum capacitors has been demonstrated. Leakage currents and breakdown voltages during step stress surge current testing (3SCT) of several types of capacitors were measured at different compressive mechanical stresses (up to $500 \mathrm{~N}$ ). Mechanisms of the stress-induced degradation in chip tantalum capacitors are discussed.

\section{Experiment}

To study the effect of compressive mechanical stresses on chip tantalum capacitors, a PC-based set-up shown in Figure 1 was used. A device under test was installed in a fixture with a top electrode connected to a stress gage (Chatillion DFGS 200) while the bottom electrode was placed on a spring. Both electrodes were isolated from the Chatillion tension/compression tester (TSD 200 ) with ceramic insulators and connected to a Keithley 236 source measure unit to monitor current variations with time and applied force. For surge current testing, the Keithley 236 instrument was replaced with a test set-up for the step stress surge current measurements, and for $\mathrm{AC}$ characteristics (capacitance, dissipation factor, DF, and effective series resistance, ESR) an impedance analyzer HP4192A was used.

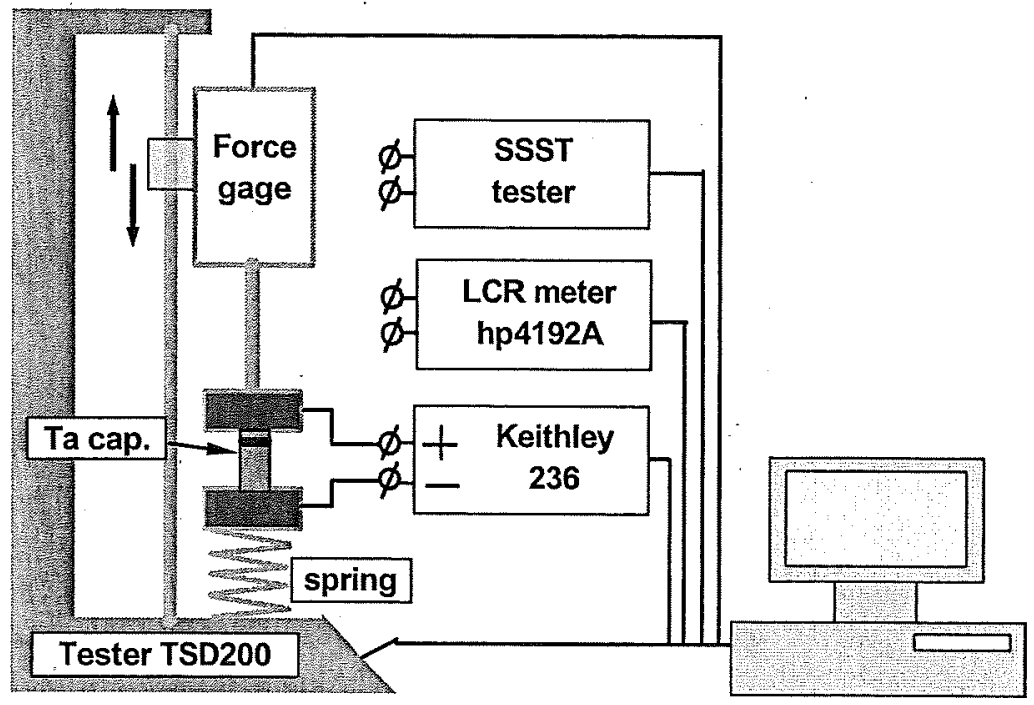

Figure 1. Experimental set-up.

During experiments, the pressure was gradually increased to a level where significant changes in the current were observed and then decreased to a safe level (typically $\sim 10 \mathrm{~N}$ ). These cycles were repeated with the maximum stress incrementally increasing to check for the effect of increasing stress and reversibility of the changes at different stress levels.

The step stress surge current testing was used to assess the effect of compressive stresses on the probability of surge current failures. During this test, a compressive stress was applied to the part, and the surge voltage was increased from the rated one in $2 \mathrm{~V}$ increments until the part failed. The testing was carried out using a PC-based data-capturing system with a field-effect transistor (FET) switch described in [12]. The current transients were monitored using an oscilloscope, and the failure event was determined when the current after the initial spike increased to more than $10 \mathrm{~mA}$. 
Parts used for the testing were commercial chip tantalum capacitors listed in Table 1. Five to 10 parts were used in each group.

Table 1. Parts used for stress testing.

\begin{tabular}{cccc}
\hline Capacitor & Type & $\begin{array}{c}\text { Case } \\
\text { Size EIA }\end{array}$ & $\mathbf{H} \times \mathbf{W} \times \mathbf{L}, \mathbf{~ m m}^{\mathbf{3}}$ \\
\hline \hline $2.2 \mu \mathrm{F} / 35 \mathrm{~V}$ & $\mathrm{~T} 491 \mathrm{C} 225 \mathrm{~K} 035 \mathrm{AS}$ & 6032 & $2.49 \times 3.34 \mathrm{X} 6$ \\
$1.5 \mu \mathrm{F} / 16 \mathrm{~V}$ & $\mathrm{~T} 491 \mathrm{~A} 155 \mathrm{~K} 016 \mathrm{AS}$ & 3218 & $1.67 \times 1.82 \mathrm{X} 3.28$ \\
$10 \mu \mathrm{F} / 16 \mathrm{~V}$ & $\mathrm{~T} 491 \mathrm{C} 106 \mathrm{~K} 016 \mathrm{AS}$ & 6032 & $2.49 \mathrm{X} 3.29 \mathrm{X} 6.08$ \\
$15 \mu \mathrm{F} / 50 \mathrm{~V}$ & $\mathrm{~T} 495 \mathrm{X} 156 \mathrm{M} 050 \mathrm{AS}$ & 7343 & $4.28 \times 4.39 \mathrm{X} 7.52$ \\
$22 \mu \mathrm{F} / 35 \mathrm{~V}$ & T491D226M035AS & 7343 & $2.85 \times 4.33 \times 7.39$ \\
\hline \hline
\end{tabular}

\section{Results}

\subsection{Effect of mechanical stresses on leakage currents}

Shown in Figure 2 are typical variations of leakage currents with time for $22 \mu \mathrm{F} / 35 \mathrm{~V}$ and 10 $\mu \mathrm{F} / 16 \mathrm{~V}$ capacitors, while the applied stress was changing periodically with increasing maximum stress. To allow for relaxation and stabilization of the current, the stress started increasing approximately $5 \mathrm{~min}$. after the rated voltage was applied to the part. The results show that when the stress reaches $\sim 50 \mathrm{~N}$ in the first case and $\sim 250 \mathrm{~N}$ in the second case, the leakage currents are increasing approximately two times. These forces were defined in this work as critical, $\mathrm{f}_{\mathrm{cr}}$. An increase of the forces above the critical level results in further increasing of the leakage currents. At great enough stresses, the currents raised approximately two orders of magnitude as seen at $\sim 250 \mathrm{~N}$ for $22 \mu \mathrm{F} / 35 \mathrm{~V}$ and at $\sim 500 \mathrm{~N}$ for $10 \mu \mathrm{F} / 16 \mathrm{~V}$ capacitors. More surprising and less easily rationalized is the fact that these changes are reversible, and a decrease of the forces to a safe level (below $\sim 10 \mathrm{~N}$ ) restored the initial levels of the currents.
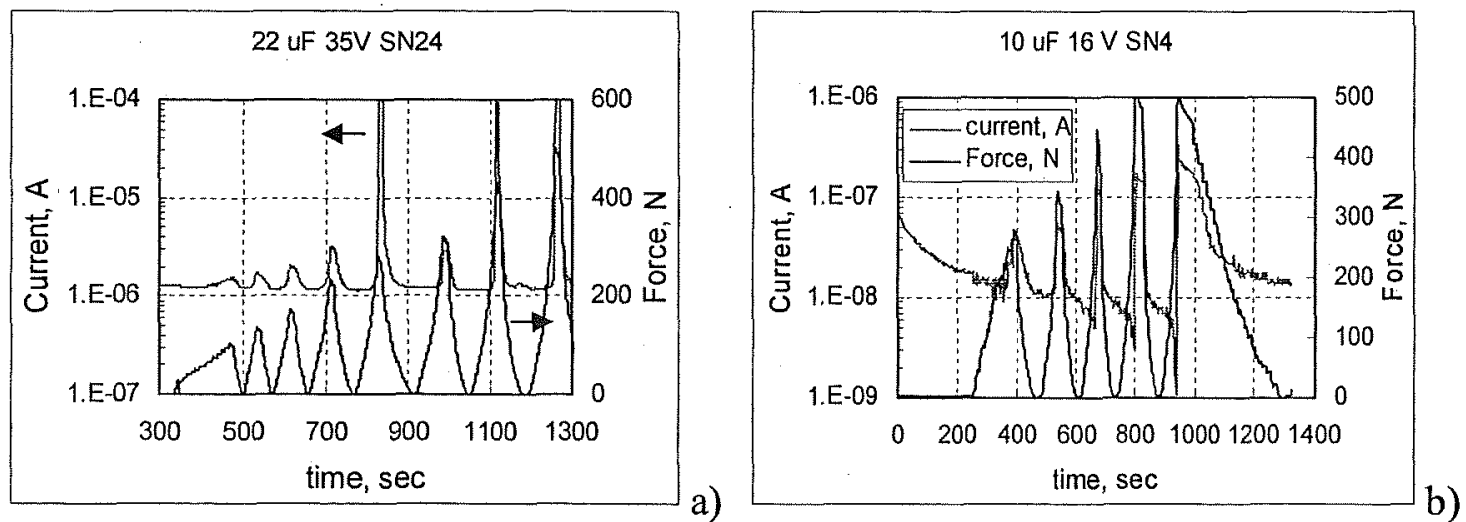

Figure 2. Typical variations of leakage currents and mechanical stresses with time for $22 \mu \mathrm{F} / 35 \mathrm{~V}$ (a) and $10 \mu \mathrm{F} / 16 \mathrm{~V}$ (b) capacitors.

Similar results were obtained for all tested lots (see Figure 3). Notably, even after a significant (more than 10 times) increase of the current, the following decrease of the force in all cases returned currents to its initial values. However, the sensitivity to the stress in some cases was decreasing, so the greater stresses did not necessarily result in greater currents. 


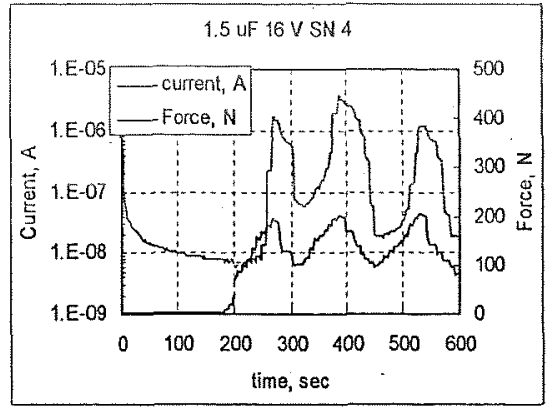

a)

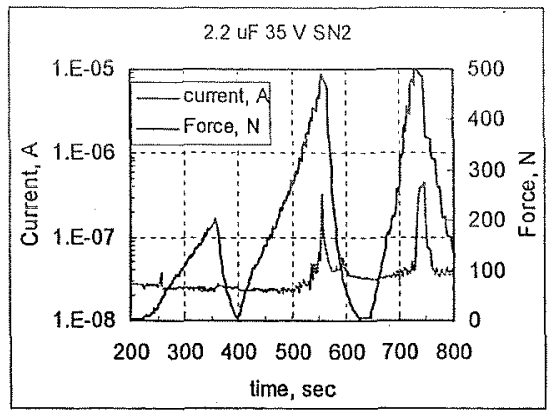

b)

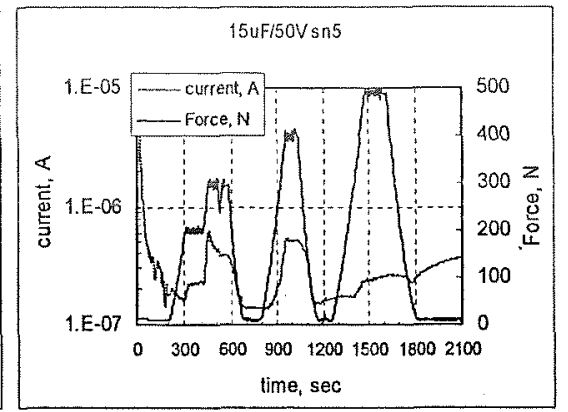

c)

Figure 3. Variations of leakage currents and mechanical stresses for $1.5 \mu \mathrm{F} 16 \mathrm{~V}$ (a), $2.2 \mu \mathrm{F} 35 \mathrm{~V}$ (b), and $15 \mu \mathrm{F} 50 \mathrm{~V}$ (c) capacitors.

The level of critical stresses varied from lot to lot and from part to part within one lot. Statistical data for $\mathrm{f}_{\mathrm{cr}}$, including average values and standard deviations, calculated for five lots are shown in Table 2. An average critical stress, $\sigma$, which is also shown in Table 2, was calculated as a ratio of the average critical force and area, $\mathrm{A}_{\text {cap }}$, of the part. The results show that the range of critical stresses in tantalum chip capacitors varies from $10 \mathrm{MPa}$ to $40 \mathrm{MPa}$, and there is no correlation between $\sigma$ and the size of the part. Note that although the critical stresses are relatively high, a large standard deviation of the distributions indicates a high probability of having samples with a relatively low $\sigma$ and respectively with a high sensitivity to mechanical stresses.

Table 2. Statistical data on critical forces and stresses in chip tantalum capacitors.

\begin{tabular}{lccccc}
\hline Capacitor & Qty. & $\begin{array}{c}\mathbf{A}_{\text {cap, }} \\
\mathbf{m m}^{2}\end{array}$ & $\begin{array}{c}\mathbf{f}_{\text {cr. avr }}, \\
\mathbf{N}\end{array}$ & $\begin{array}{c}\text { St. } \\
\text { Dev. }\end{array}$ & $\begin{array}{c}\sigma, \\
\text { MPa }\end{array}$ \\
\hline $2.2 \mu \mathrm{F} / 35 \mathrm{~V}$ & 5 & 8.3 & 323 & 45 & 38.8 \\
$1.5 \mu \mathrm{F} / 16 \mathrm{~V}$ & 5 & 10.0 & 205 & 29 & 20.6 \\
$10 \mu \mathrm{F} / 16 \mathrm{~V}$ & 5 & 8.2 & 311 & 127 & 38.0 \\
$15 \mu \mathrm{F} / 50 \mathrm{~V}$ & 7 & 18.8 & 441 & 201 & 23.5 \\
$22 \mu \mathrm{F} / 35 \mathrm{~V}$ & 14 & 12.3 & 134 & 71 & 10.9 \\
\hline
\end{tabular}

Figure 4a shows characteristics of a $22 \mu \mathrm{F} / 35 \mathrm{~V}$ capacitor where the stress was varied in such a way to allow estimation of the current-force relationship. Note that for this part, an increase in $f$ to $\sim 400 \mathrm{~N}$ resulted in a current spike with amplitude of more than $100 \mu \mathrm{A}$ (compliance current limit). However, even in this case, after the current increased almost three orders of magnitude, a reduction of the force to below $100 \mathrm{~N}$ reduced the current to a sub-microampere level, which is only slightly above the initial current.

The $I(f)$ relationship plotted based on the data presented in Figure $4 \mathrm{a}$ is shown in Figure $4 \mathrm{~b}$ and suggests an exponential dependence of the current on compressive stresses:

$$
I=B \times \exp (\alpha \times f),
$$

where $\alpha$ and $\mathrm{B}$ are empirical coefficients. Estimations showed that the coefficient $\alpha$ is in the range from $0.00821 / \mathrm{N}$ to $0.00851 / \mathrm{N}$. 

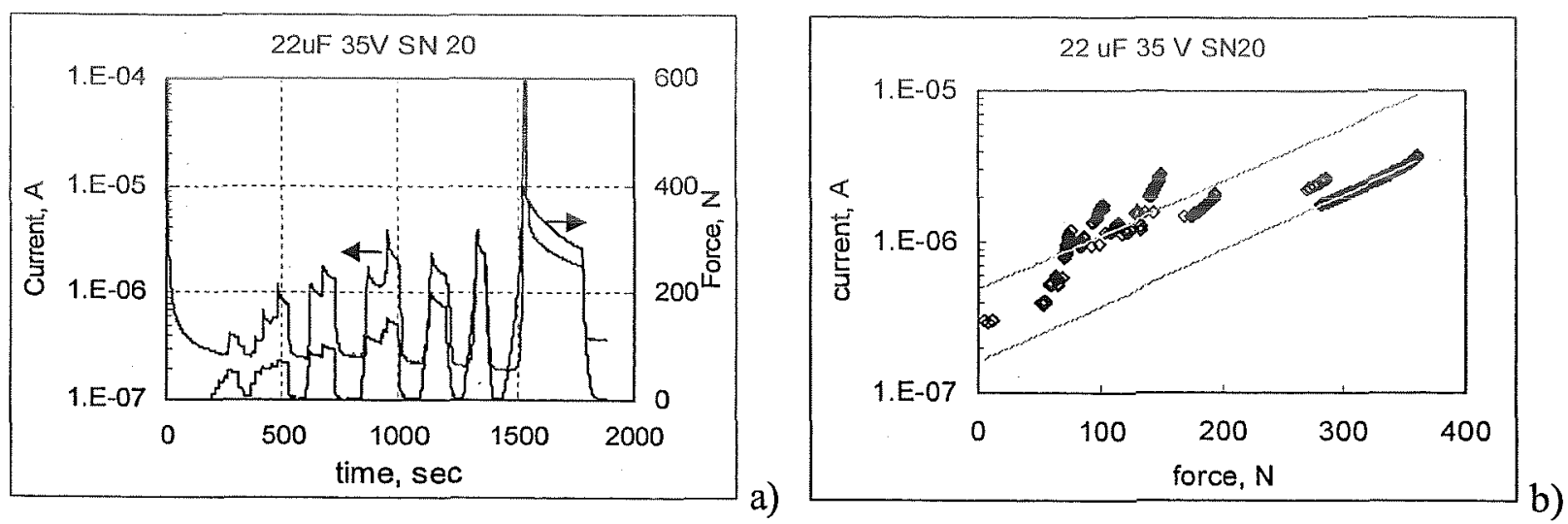

Figure 4. Variations of leakage currents and mechanical stresses with time for a $22 \mu \mathrm{F} 35 \mathrm{~V}$ capacitor (a) and dependence of the current on applied force (b).

To get a more accurate $I(f)$ relationship, variations of the current with stresses were measured on four more $22 \mu \mathrm{F} / 35 \mathrm{~V}$ capacitors. In these experiments, mechanical stresses were stabilized at different levels for $\sim 3 \mathrm{~min}$. to allow for current stabilization. Typical results of these tests are shown in Figure 5a. In some cases, application of stress results in current spikes exceeding 100 $\mu \mathrm{A}$. However, the stabilized currents are apparently independent of the initial spike and vary with the level of the stress, suggesting that the stress affects intrinsic leakage currents in the parts rather than trigging electrical breakdown of the dielectric. Note also that there is a time delay of a few seconds between the stress and current variations.

Current versus force characteristics for four $22 \mu \mathrm{F} 35 \mathrm{~V}$ capacitors are shown in Figure $5 \mathrm{~b}$. The results confirmed that leakage currents increase exponentially with the stress, and the coefficient $\alpha$ in Eq. 1 varies in a relatively narrow range from $0.00631 / \mathrm{N}$ to $0.00881 / \mathrm{N}$.
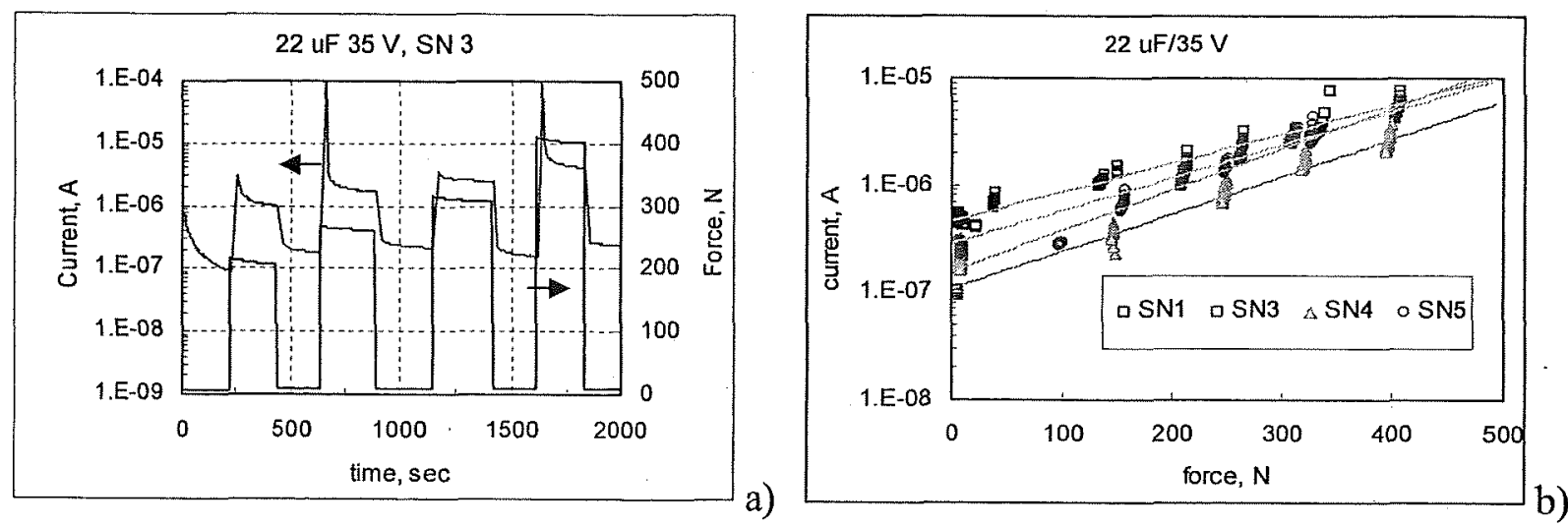

Figure 5. Typical current variations in a $22 \mu \mathrm{F} / 35 \mathrm{~V}$ capacitor when compressive stresses were stabilized at different levels (a) and effect of the stress on leakage currents for four parts (b).

One might suspect that the observed effect is specific to tantalum capacitors with manganese cathodes only and is due to the presence of manganese crystals. These crystals are capable of creating significant mechanical stresses and were hypotized to be responsible for failures in tantalum capacitors [13].

To check whether the stress effect is specific to tantalum capacitors with manganese cathode only, two types of capacitors, $150 \mu \mathrm{F} / 3 \mathrm{~V}$ and $100 \mu \mathrm{F} / 4 \mathrm{~V}$, with polymer cathodes were used. Results of 
measurements under variable stress conditions for these parts are shown in Figure 6 and clearly indicate that the stress-induced leakage currents vary reversibly in polymer capacitors similar to the manganese cathodes parts.
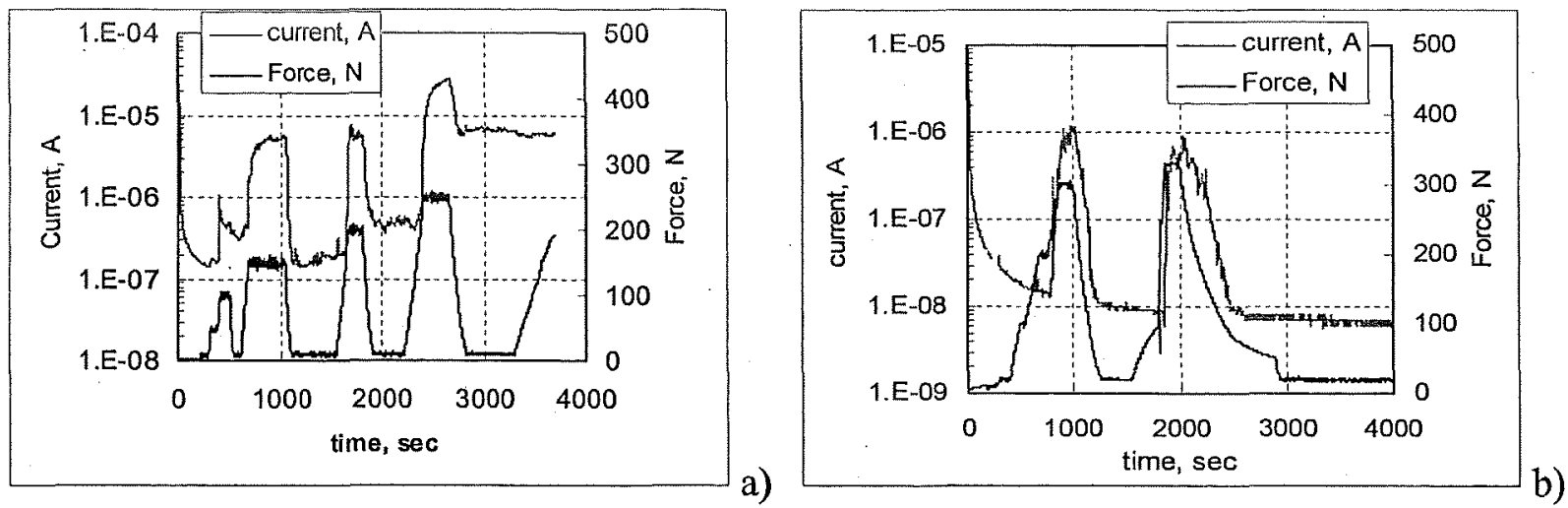

Figure 6. Variations of leakage currents and applied stresses in $150 \mu \mathrm{F} 3 \mathrm{~V}$ (a) and $100 \mu \mathrm{F} 4 \mathrm{~V}$ (b) polymer tantalum capacitors.

\subsection{Effect of mechanical stresses on capacitance}

Typical variations of the capacitance (C) and dissipation factor (DF) for a $22 \mu \mathrm{F} / 35 \mathrm{~V}$ part measured with time, while the compressive stress gradually increased up to $500 \mathrm{~N}$, are shown in Figure 7. Both AC characteristics remained stable within the accuracy of the measurements, indicating that $\mathrm{C}$ and $\mathrm{DF}$ are not sensitive to mechanical stresses. It is important to note that this behavior is different compared to ceramic capacitors (X7R/X5R types), where mechanical stresses do cause changes in the $\mathrm{AC}$ characteristics. This, as well as the presence of the piezo-effect in ceramic capacitors, results in different behavior of tantalum and ceramic capacitors in the presence of mechanical disturbances.

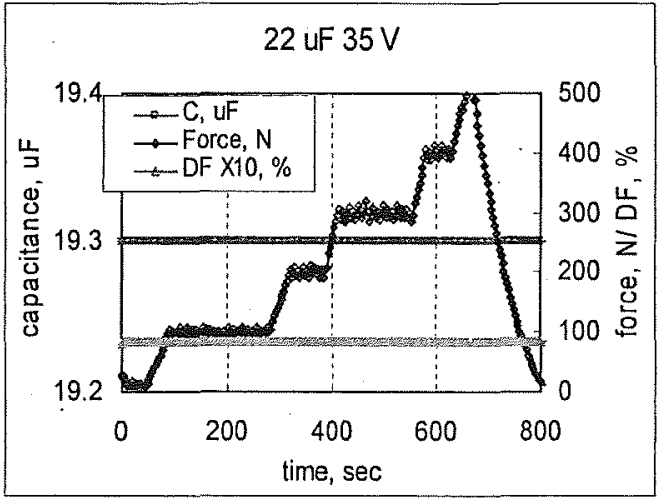

Figure 7. Variations of capacitance, dissipation factor, and compressive stress with time for a 22 $\mu \mathrm{F} / 35 \mathrm{~V}$ capacitor.

A comparison of the behavior between tantalum and ceramic chip capacitors regarding their reaction to mechanical stress variations is shown in Figure 8. During these experiments, leakage currents in the parts were monitored while the stress varied periodically from $9 \mathrm{~N}$ to $14 \mathrm{~N}$. It is seen that these stresses did not affect leakage currents in tantalum capacitors, whereas significant noise was generated in ceramic parts. 

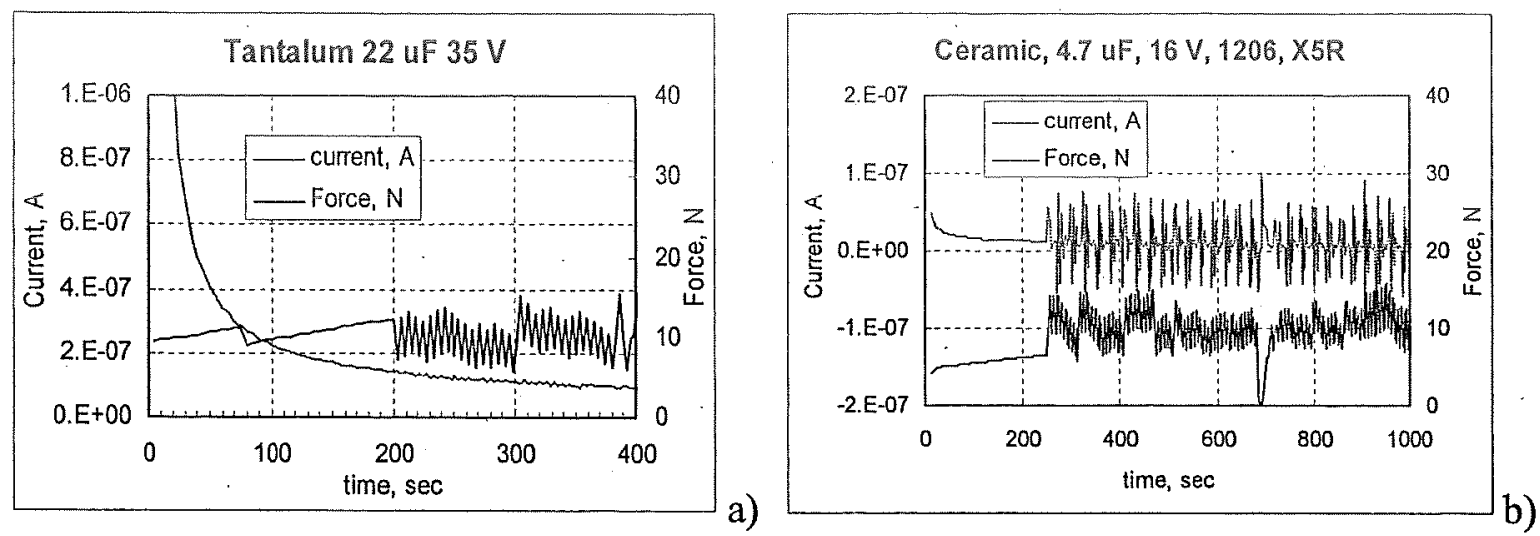

Figure 8. Reaction of tantalum (a) and ceramic (b) capacitors to mechanical noise generated by periodical variations of the force between $9 \mathrm{~N}$ and $14 \mathrm{~N}$.

\subsection{Effect of mechanical stresses on surge current failures}

To assess the effect of mechanical stresses on surge current failures, five $22 \mu \mathrm{F} / 35 \mathrm{~V}$ capacitors were tested using a step stress surge current testing (3SCT) technique while the parts were stressed with a force of $100 \mathrm{~N}$. A control group of samples was tested in the same set-up, but at a low compressive force of $\sim 10 \mathrm{~N}$ or less.

To assure that the stress of $100 \mathrm{~N}$ would not cause failures when the rated voltage was applied, current variations in the parts were monitored prior to the surge current testing. Results of these experiments are shown in Figure 9 and indicate no variations or relatively minor increase in the currents, which all remained well below the specified limit of $7.7 \mu \mathrm{A}$ for this device. Note also that in some cases the current starts increasing with time after the force is stabilized. The time required for current to reach a steady-state condition varies from 10 to 50 seconds and corresponds to the time delays observed in the experiments described above.
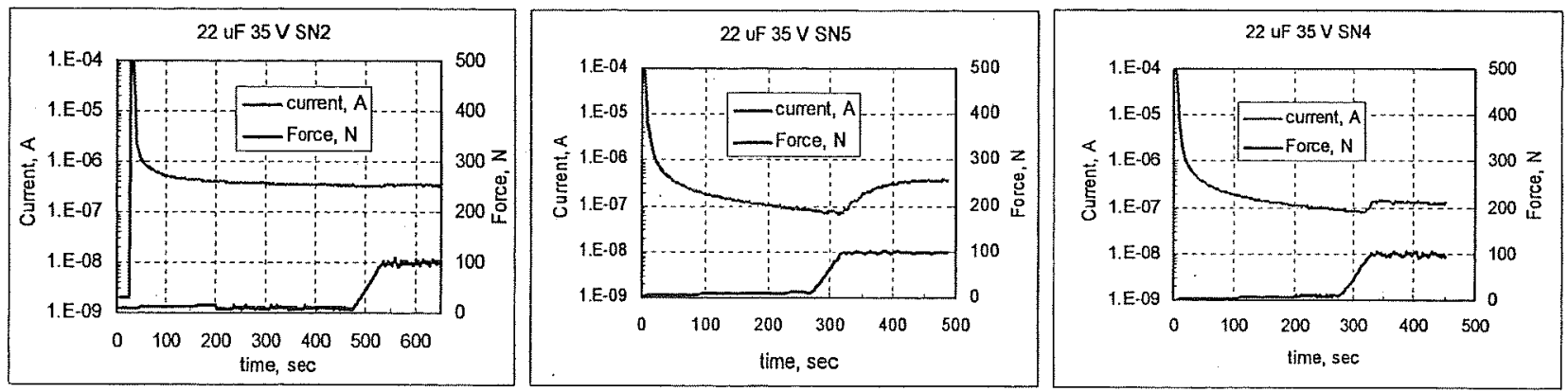

Figure 9. Variations of currents due to application of a force of $100 \mathrm{~N}$ in three $22 \mu \mathrm{F} / 35 \mathrm{~V}$ capacitors.

Weibull distributions of the breakdown voltages measured for the control group and for devices stressed with $100 \mathrm{~N}$ are plotted in Figure 10 and indicate a significant decrease in the breakdown voltages caused by the stress. The characteristic breakdown voltage decreased from $66.7 \mathrm{~V}$ initially to $46.7 \mathrm{~V}$ when the force was applied. 


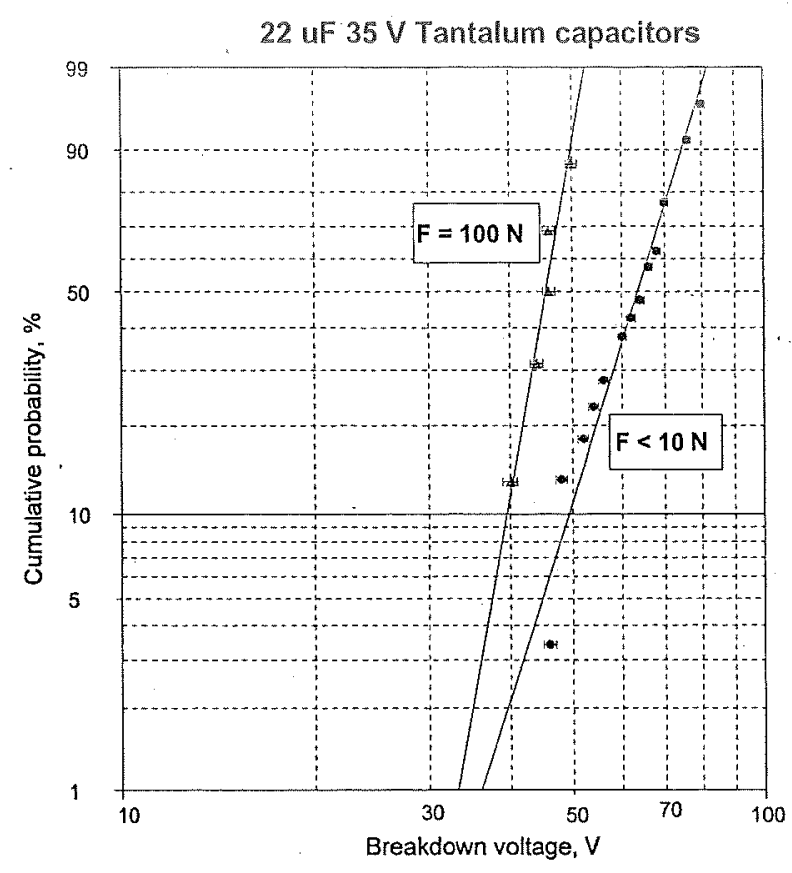

Figure 10. Weibull distributions of breakdown voltages measured during step stress surge current testing (3SCT).

\section{Effect of mechanical stresses caused by conformal coating}

To simulate the effect of mechanical stresses developing in capacitors due to application of conformal coatings in a controllable way, 15 samples of $22 \mu \mathrm{F} / 35 \mathrm{~V}$ parts with short $(\sim 1$ inch) soldered wires were potted into a low-stress, room-temperature curing, Struers EPOFIX epoxy. The parts were characterized initially and then after curing of the epoxy at different conditions, which were expected to increase the level of the stress in the parts. First, the parts were cured at room temperature for 15 hours, then at $130{ }^{\circ} \mathrm{C}$ for 15 hours, and finally at $150{ }^{\circ} \mathrm{C}$ for 15 hours. The curing-induced strain (shrinkage), $\mathrm{S}$, was measured with a strain gage potted in the epoxy together with the parts.

Measurements of $\mathrm{AC}$ characteristics in the parts after different curing conditions indicated no significant variations in capacitance and ESR values, whereas leakage currents (see Figure 11) increased substantially after curing at high temperatures. Note that an increase in currents coincides with the onset of the strain in the epoxy.

To estimate mechanical stresses caused by the potting epoxy, thermo-mechanical characteristics of the material and capacitors were measured using a thermo-mechanical analyzer TMA2940. Young's modulus of the potting material, E, was estimated based on room-temperature measurements of deformations in a sample under a stress of $\sim 0.5 \mathrm{MPa}$. Results of these measurements are shown in Table 3. It is seen that a high-temperature curing significantly increases the Young's modulus and the strain, whereas the values of CTE and glass transition temperature increase to a much lesser degree. 


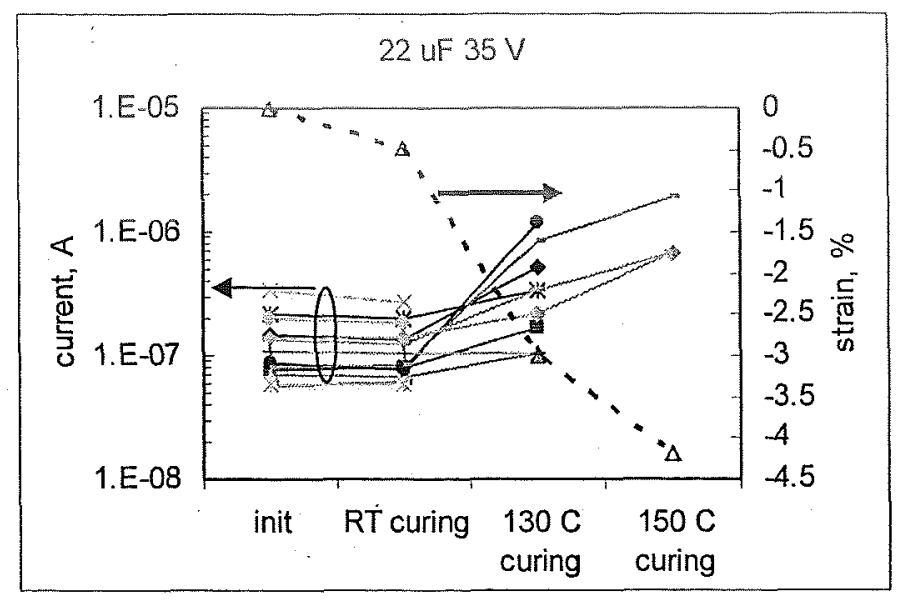

Figure 11. Effect of curing conditions on leakage currents in capacitors and strain in the epoxy compound.

Table 3. Thermo-mechanical characteristics of potting epoxy cured at different conditions.

\begin{tabular}{ccccc}
\hline Condition & $\begin{array}{c}\mathbf{C T E}, \\
\mathbf{p p m} /{ }^{\circ} \mathbf{C}\end{array}$ & $\mathbf{T g},{ }^{\circ} \mathbf{C}$ & $\mathbf{E}, \mathbf{G P a}$ & $\begin{array}{c}\text { Strain, } \\
\%\end{array}$ \\
\hline RT Curing & 82 & 65 & 0.32 & 0.48 \\
$130^{\circ} \mathrm{C}$ Curing & 72 & 70 & 1.25 & 3.1 \\
$150{ }^{\circ} \mathrm{C}$ Curing & 70 & 78 & 2.41 & 4.2 \\
\hline
\end{tabular}

Based on these data, mechanical stresses created by the potting epoxy in tantalum capacitors were estimated as a sum of CTE-mismatch-induced and shrinkage-induced stresses using the following equation:

$$
\sigma=E \times\left(\alpha_{P E}-\alpha_{c a p}\right) \times\left(T_{g}-T_{a}\right)+E \times S,
$$

where $\alpha_{\mathrm{PE}}$ and $\alpha_{\mathrm{cap}}\left(\sim 7 \mathrm{ppm} /{ }^{\circ} \mathrm{C}\right)$ are the coefficients of thermal expansion of the potting epoxy and tantalum capacitor, and $T_{a}$ is the ambient temperature. Results of these calculations are shown in Table 4 and indicate that curing at high temperatures creates stresses that are above the level of the critical stresses shown in Table 2. Note also that most stresses in high-temperature cured epoxy were caused by curing-induced shrinkage, whereas the CTE mismatch-induced stresses were only $\sim 8$ to $12 \%$ of the total stresses. The results indicate that both, the level of compressive stresses and the degree of the increase of leakage currents are in agreement with the direct experiments described above.

Table 4. Stresses in tantalum capacitors caused by potting epoxy cured at different conditions.

\begin{tabular}{cccc}
\hline \hline Condition & $\begin{array}{c}\text { CTE } \\
\text { Stress, } \\
\mathbf{M P a}\end{array}$ & $\begin{array}{c}\text { Curing } \\
\text { Stress, } \\
\mathbf{M P a}\end{array}$ & $\begin{array}{c}\text { Total } \\
\text { Stress, } \\
\mathbf{M P a}\end{array}$ \\
\hline RT Curing & 1.1 & 1.5 & 2.6 \\
$130^{\circ} \mathrm{C}$ Curing & 4.1 & 38.8 & 42.8 \\
$150^{\circ} \mathrm{C}$ Curing & 8.8 & 101 & 110 \\
\hline
\end{tabular}


Step stress surge current testing was carried out on two groups with six samples each after roomtemperature curing and $130^{\circ} \mathrm{C}$ curing and on a group of three samples after $150^{\circ} \mathrm{C}$ curing. Results of these tests, together with the data obtained on a separate group of 20 samples tested without epoxy coating, are shown in Table 5.

Table 5. Effect of curing conditions on step stress surge current testing (3SCT) of $22 \mu \mathrm{F} / 35 \mathrm{~V}$ capacitors.

\begin{tabular}{ccccc}
\hline & Initial & $\begin{array}{c}\text { RT } \\
\text { Curing }\end{array}$ & $\begin{array}{c}\mathbf{1 3 0}{ }^{\circ} \mathrm{C} / \mathbf{1 5} \\
\text { Hrs. }\end{array}$ & $\begin{array}{c}\mathbf{1 5 0}{ }^{\circ} \mathrm{C} / \mathbf{1 5} \\
\text { Hrs. }\end{array}$ \\
\hline \hline VBR_3SCT, V & 62.7 & 68.3 & 52 & 42.3 \\
Std. Dev. & 10.1 & 10.7 & 9.9 & 7.0 \\
Qty. & 20 & 6 & 6 & 3 \\
\hline \hline
\end{tabular}

Analysis of these data using Student's t-tests showed that a decrease of the breakdown voltages after additional high-temperature curing of the potting epoxy is significant at $95 \%$ confidence level, whereas the effect of room-temperature curing is negligible.

The results show that hydrostatic stresses created by potting epoxy result in degradation of leakage currents and breakdown voltages similar to the axial forces. Conformal coatings might affect performance and reliability of chip tantalum capacitors, and the effect might be especially significant for small-sized parts coated with relatively thick layers of polymers having high Young's modulus and great curing-related shrinkage.

\section{Discussion}

The observed results can be explained by a combination of two mechanisms: stress-induced scintillations and stress-induced generation of electron traps in tantalum pentoxide dielectric. The first mechanism occurs at relatively great forces, far exceeding the critical ones, and is due to formation of macro-defects in the dielectric (e.g., cracking). Formation of these defects can trigger a local momentary breakdown followed by the self-healing process, which is well known in solid tantalum capacitors with manganese cathodes $[14,15]$ and was observed recently even in polymer tantalum capacitors [16]. The scintillations result in relatively large current spikes and might cause irreversible increase of the leakage current due to incomplete conversion of the conductive $\mathrm{MnO}_{2}$ into a high-resistive $\mathrm{Mn}_{2} \mathrm{O}_{3}$ phase and/or not complete coverage of the whole area of the defective dielectric with $\mathrm{Mn}_{2} \mathrm{O}_{3}$. However, scintillations cannot explain reversible variations in the leakage currents observed in our experiments after the stress removal.

The second mechanism, trap generation, is due to a stress-induced formation of microscopic defects, such as broken Ta-O bonds, and generation of oxygen vacancies, which increase the concentration of electron traps in the dielectric. According to the Pool-Frenkel mechanism, which is a prevailing mechanism of conductivity in thin tantalum pentoxide films at normal operating conditions[17], the density of leakage current can be described by the following expression:

$$
J=C_{t} E \exp \left(-\frac{q \Phi}{k T}\right) \exp \left(-\frac{\beta_{P F} E^{1 / 2}}{k T}\right)
$$

where $C_{t}$ is a trap density related constant, $E$ is the electric field, $q$ is the charge of the electron, $\Phi$ is the barrier height, $k$ is the Boltzmann constant, and $T$ is the absolute temperature. The PoolFrenkel constant $\beta_{\mathrm{PF}}$ is: 


$$
\beta_{P F}=\left(\frac{q^{3}}{\pi \varepsilon_{0} \varepsilon}\right)^{1 / 2},
$$

where $\varepsilon_{0}$ is the permittivity of free space, and $\varepsilon$ is the high-frequency dielectric constant.

The trap concentration is determined by a dynamic equilibrium of two concurring and competitive processes: generation of stress-induced defects and their annealing (e.g., recombination of the broken bonds). When the stress is removed, the concentration of the traps returns to its initial value and so does the leakage current. Both generation under the stress and recombination after stress removal develop. with time, and based on our data, the characteristic time of the process is in the range of a few seconds to dozens of seconds. Considering exponential dependence of the leakage current on the stress, it is reasonable to assume that the concentration of the electron traps also increases exponentially with the stress.

It should be noted that a similar mechanism related to the enhanced bond breaking due to physical stresses was used to explain factors affecting reliability of gate oxides in microcircuit $[18,19]$. The effect of mechanical stresses on the rate of failures caused by the time-dependent dielectric breakdown (TDDB) in the gate-oxide films of MOS transistors was demonstrated in [20]. It was shown that time to failure decreased almost two orders of magnitude as stresses in the oxide increased from $80 \mathrm{MPa}$ to $170 \mathrm{MPa}$.

The TDDB effect in solid tantalum capacitors was demonstrated in [21] more than 40 years ago. The mechanism of this effect was explained similarly to the TDDB in $\mathrm{SiO}_{2}$ films by a degradation of the dielectric through creation of defective microscopic sites, such as broken bonds and their accumulation with time to the moment when a critical density of the defects is forming a conductive path, resulting in a thermal runaway breakdown [22].

Mechanical stresses cause strain in the atomic bonds in a dielectric, thus weakening them and enhancing the rate of de-bonding and generation of the defects in the presence of high electrical fields. Accumulation of these defects with time to a degree to which it affects conduction of the tantalum pentoxide dielectric explains also the time-dependent effects and hysteresis observed during measurements of stress-induced leakage currents.

The value of pressure that causes trap generation is obviously not equal to the average pressure in the package of the part. Due to the sponge-like structure of the tantalum capacitor, mechanical stresses in the package create local stresses in the dielectric, which are spread over the whole slug not uniformly, so in some locations the stress can be substantially greater than an average stress in the package. These locations are most likely responsible for increased leakage currents in the stressed capacitors.

\section{Conclusion}

- The effect of compressive stresses on different types of chip tantalum capacitors has been investigated by monitoring characteristics of the parts while the stress applied to the terminals varied up to $500 \mathrm{~N}$.

- No significant variations in AC characteristics of the capacitors were observed. However, at stresses exceeding a certain critical level, leakage currents increased exponentially with the stress and at sufficiently great stresses exceeded the initial currents on more than two orders of magnitude. Different part types have different sensitivity to mechanical stresses, and the average level of critical stresses varied from $10 \mathrm{MPa}$ to $40 \mathrm{MPa}$. 
- The most interesting feature of the stress-induced currents is that they are completely reversible at relatively low stresses, thus ruling out a simple "damage-induced" mechanism of the phenomenon. After application of sufficiently great stresses only, the currents do not recover completely after the stress removal.

- Compressive stresses might significantly increase the probability of surge current failures. Application of a stress of $100 \mathrm{~N}$ to $22 \mu \mathrm{F} / 35 \mathrm{~V}$ capacitors reduced the characteristic breakdown voltage from $66.7 \mathrm{~V}$ initially to $46.7 \mathrm{~V}$.

- Capacitors with polymer cathodes have demonstrated stress-induced leakage currents similar to the manganese cathode capacitors. This indicates that the effect is not related to the type of the cathode used and is a characteristic feature of the $\mathrm{Ta}-\mathrm{Ta}_{2} \mathrm{O}_{5}$ system.

- The hydrostatic pressure created in tantalum capacitors by epoxy coating affects leakage currents and surge current breakdown voltages similar to the axial stresses.

- The effect of variations of leakage currents with stresses was explained by reversible changes of the concentration of electron traps under local stresses in the tantalum pentoxide dielectric. These traps enhance the conductivity of $\mathrm{Ta}_{2} \mathrm{O}_{5}$ according to the Pool-Frenkel mechanism, and variations of their concentration with time explain hysteresis and time delay effects in the stress-induced leakage currents. Large current spikes of more than two orders of magnitude and irreversible portion of leakage current variations at high enough stresses are most likely due to the formation of macro-defects (e.g., micro-cracks) and scintillation breakdowns in the parts.

\section{Acknowledgement}

This work was supported by the GSFC projects, code 562, and NASA Electronic Parts and Packaging Program, NEPP.

\section{References}

[1] S. Gee, T. Doan, K. Gilbert, "Stress related offset voltage shift in a precision operational amplifier", in Proceedings of the 43rd Electronic Components and Technology Conference, 1993, 1-4 Jun, pp. $755-764$.

[2] J.F. Creemer, F. Fruett, G.C. Meijer, P.J. French, "The piezojunction effect in silicon sensors and circuits and its relation to piezoresistance", Sensors Journal, IEEE, 2001, 1(2), pp. 98-108.

[3] J. Prymak, M. Prevallet, P. Blais, B. Long, "New Improvements in Flex Capabilities for MLC Chip Capacitors", in Proceedings of the The 26th symposium for passive components, CARTS'06, 2006, April 3-6, 2006, Orlando, FL, pp. 63-76.

[4] M.J. Cozzolino, "Stress determination for surface mounted ceramic capacitors", in Proceedings of the The 6th symposium for passive components, CARTS'86, 1986, March 12-14, New Orleans, LA, pp. 42-52.

[5] D.D. Chang, F.R. Anderson, "Effect of Board Design \& Assembly Process on Leakage Currents of Ceramic Chip Capacitors", 40th Electronic Components and Technology Conference, 1990, 2, pp. 1035-1041.

[6] D.S. Erdahl, I.C. Ume, "Online-Offline Laser Ultrasonic Quality Inspection Tool for Multilayer Ceramic Capacitors", IEEE TRANSACTIONS ON ADVANCED PACKAGING, 2004, 27(4), pp. 647-653.

[7] M. Keimasi, M. Azarian, M. Pecht, "Comparison of Flex Cracking of Multilayer Ceramic Capacitors Assembled with Lead-Free and Eutectic Tin Lead", in Proceedings of the The 26th symposium for passive components, CARTS'06, 2006, April 3-6, 2006, Orlando, FL, pp. 15-24.

[8] B.Long, M.Prevallet, J.D.Prymak, "Reliability Effects with Proofing of Tantalum Capacitors", in Proceedings of the The 25th Symposium for Passive Components, CARTS'05, 2005, March 21-24, 2005, Palm Springs, California, pp. 167-172.

[9] J. Marshall, J. Prymak, "Surge step stress testing of tantalum capacitors", in Proceedings of the 21st Capacitors and Resistors Technology Symposium, CARTS'01, 2001, pp. 181-187. 
[10] B. Long, M. Prevallet, J.D. Prymak, "Reliability Effects with Proofing of Tantalum Capacitors", in Proceedings of the The 25th Symposium for Passive Components, CARTS05, 2005, March 21-24, 2005, Palm Springs, California, pp. 167-172.

[11] D.M. Edson, J.B. Fortin, "Improving thermal shock resistance of surface mount tantalum capacitors", in Proceedings of the 14th Capacitors and Resistors Technology Symposium, 1994, 21-24 March, Jupiter, FL, pp. $169-176$.

[12] A. Teverovsky, "Effect of Infductance and Requirements for Surge Current Testing of Tantalum Capacitors", in Proceedings of the CARTS'03, the 26th Symposium for Passive Components, 2006, April 3-6, 2006, Orlando, FL, pp. 363-384.

[13] P. Fagerholt, "A new view on failure phenomena in solid tantalum capacitors", in Proceedings of the 16th Capacitors and Resistors Technology Symposium, CARTS'96, 1996, March 11-15, 1996, pp. 162-166.

[14] M.J. Cozzolino, R.C. Straessle, "Design, characteristics, and failure mechanisms of tantalum capacitors", in Proceedings of the 8th CARTS'88, 1988, March 9-10, 1988, San Diego, CA, pp. 98-110.

[15] H.W. Holland, "Solid tantalum capacitor dielectric failure mechanism and determination of failure rate", KEMET Engineering bulletin, 1998(4).

[16] J. Prymak, M. Prevallet, "Scintillation Testing of Solid Electrolytic Capacitors", in Proceedings of the The 26th symposium for passive components, CARTS'06, 2006, April 3-6, 2006, Orlando, FL, pp. 395-406.

[17] E. Atanassova, A. Paskaleva, "Conduction mechanisms and reliability of thermal Ta2O5-Si structures and the effect of the gate electrode", Journal of Applied Physics, 2005, 97, pp. 1-11.

[18] Y. Ohno, A. Ohsaki, T. Kaneoka, J. Mitsuhashi, M. Hirayama, and T. Kato, "Effect of mechanical stress for thin SiO2 films in TDDB and CCST characteristics", in Proceedings of the 27th Annual International Reliability Physics Symposium, 1989, 11-13 April, pp. 34-38.

[19] T.C. Yang, K.C. Saraswat, "Effect of Physical Stress on the Degradation of Thin SiO2 Films Under Electrical Stress", IEEE transections on electron devices, 2000, 47(4), pp. 746-755.

[20] H.I. Miura, S.; Suzuki, N.; "Effect of mechanical stress on reliability of gate-oxide film in MOS transistors", International Electron Devices Meeting, 1996, pp. 743-746.

[21] L. Howard, A. Smith, "Dielectric Breakdown in Solid Electrolyte Tantalum Capacitors", IEEE Transactions on Component Parts,, 1964, 11(2), pp. $187-193$.

[22] K.H. Allers, R. Schwab, W. Walter, M. Schrenk, H. Korner, "Thermal and dielectric breakdown for metal insulator metal capacitors (MIMCAP) with tantalum pentoxide dielectric", in Proceedings of the IEEE International Integrated Reliability Workshop Final Report, 2002, 21-24 Oct. 2002, pp. 96-101. 